DE91 000088

\title{
Explosive Inventory Program
}

\author{
Larry A. Lewis \\ Range Operations Division \\ Ron S. Taylor \\ Optical Measurement Division \\ Sandia National Laboratories \\ Tonopah Test Range \\ 'Tonopah, NV 89049
}

\begin{abstract}
This report describes the computer program used at the Tonopah Test Range to maintain the explosive inventory. The program, which uses dBASE III or dBASE III Plus and runs on an IBM PC or compatible, has the capabilities to update (add or subtract) items, edit or delete, append, and generate various reports.
\end{abstract}




\section{Contents}

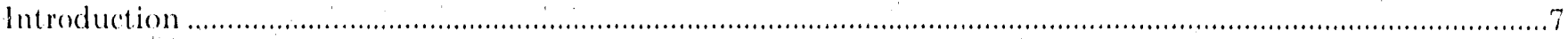

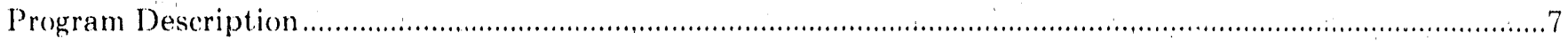

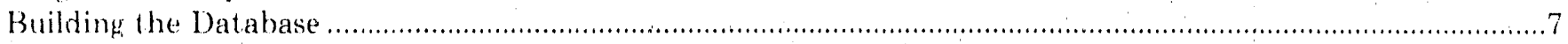

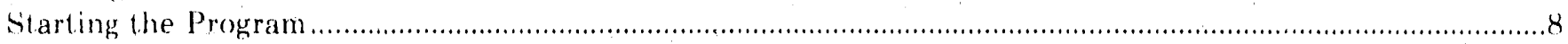

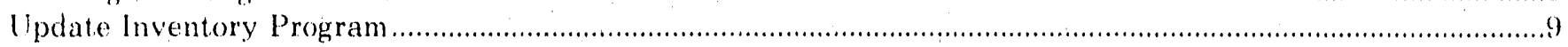

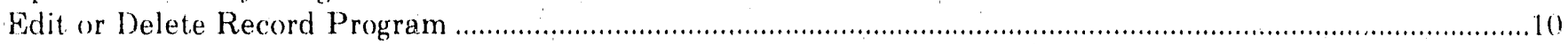

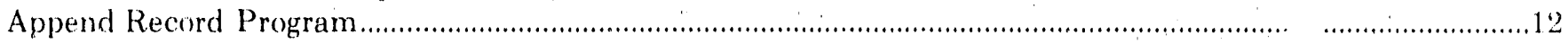

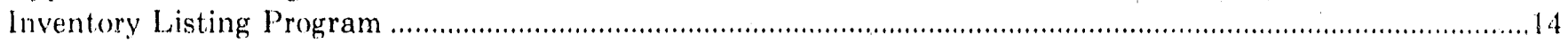

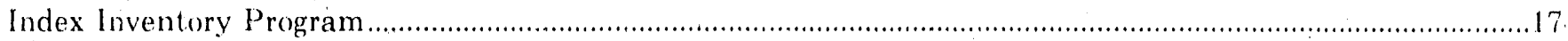

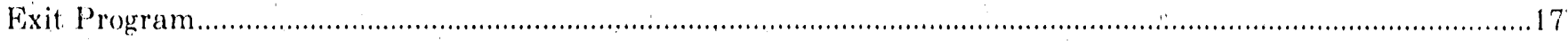

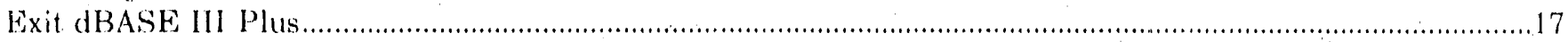

\section{Figures}

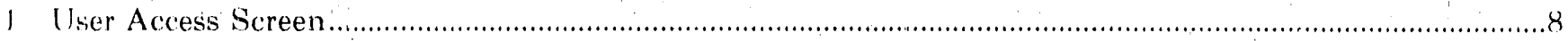

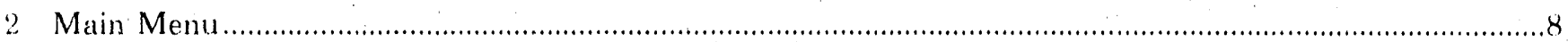

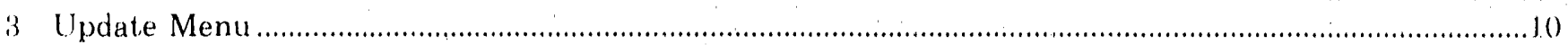

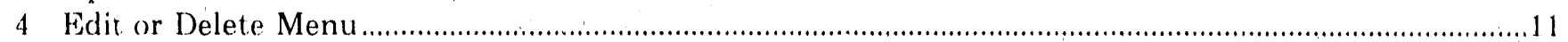

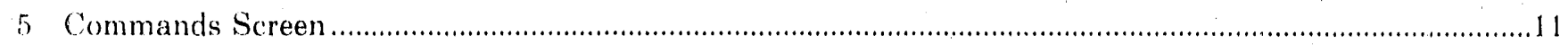

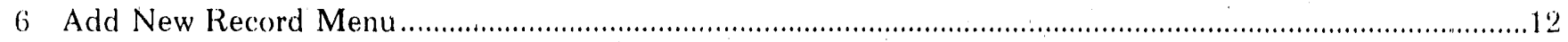

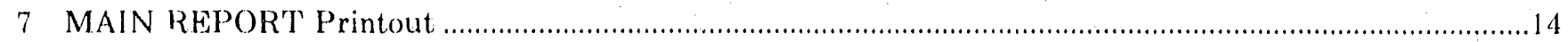

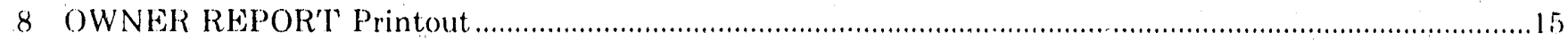

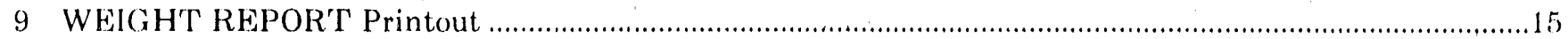

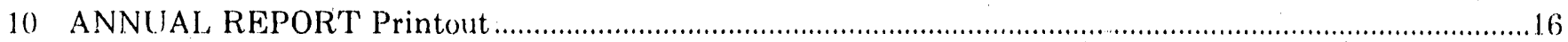

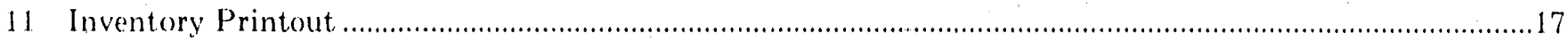

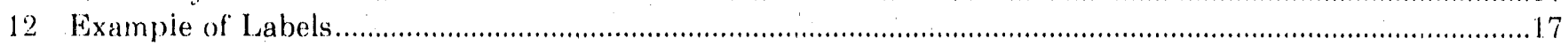

\section{Table}

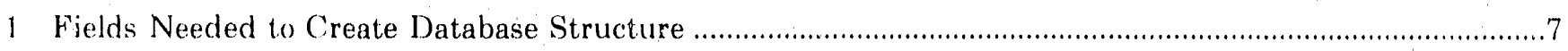




\section{Explosive Inventory Program}

\section{Introduction}

The Explosive Inventory program was designed to perform the following functions:

- Update the inventory as items are received and expended. The program can perform calcula. tions of addition, subtraction, and inultiplication.

- Edit records.

- Delete records.

- Add records.

- Generate various reports.

- Create labels for inventory items.

- Calculate the total number of items, totai item weight. total explosive weight per bunker, and total explosive weight of all bunkers.

\section{Program Description}

The Explosive Inventory program was developed to keep an accurate inventory of all explosives stored at the 'T'mopah T'est Range ('T'l'R). The program can calculate additions and subtractions of items used and received. It can also calcralate total item weight. and total bunker explosive woight.

With this program, one can edit, delote, and create new records by using the Append program whenever new items are received. Four different types of reports can be generated by this program: (1) the Main Report, for a broad overview; (2) the Owner Report, which lists who owns what items; (3) the Weight Report, which gives total item weight and total explosive storage bunker weight; and (4) the Year-End Report, which compares quantity of explosives in the initial inventory against quality at year's end, as well as weight totals.

In addition, the program is capable of generating; adhesive labels used to identify items.

\section{Building the Database}

'I'he first item that must be created is the explo. sive database structure. T'o do this, refer to the dPASE III or III Plus manual. Table 1 lists the fields that are needed for the program to work correctly.

\section{Table 1. Fields Needed to Create Database Structure}

\begin{tabular}{|c|c|c|c|c|}
\hline Field & Name & Type & Width & Dec \\
\hline 1 & ITEM & Character & 20 & \\
\hline 2 & I.O'T' NUMBFR & Character & 20 & \\
\hline 3 & I.OCA'TION & Character & 8 & \\
\hline 4 & $\mathrm{BIN}$ & Character & 3 & \\
\hline 5 & LAST' INV'TY & Date & 8 & \\
\hline 6 & INVTY QUIAN & Numeric & 5 & \\
\hline 7 & QUAN USHI) & Numeric & 5 & \\
\hline 8 & CURN'QUAN & Numeric: & 5 & \\
\hline 9 & UNITS & Character & 2 & \\
\hline 10 & UNIT'W' W & Numeric: & 8 & 3 \\
\hline 11 & CURNT W' W' & Numeric: & 8 & 3 \\
\hline 12 & OWNER & Character & 10 & \\
\hline 13 & COMMEN'TS & Character & 20 & \\
\hline 14 & HAZ (IAASS & Character & 1 & \\
\hline 15 & COMP (IROUP & Character & 1 & \\
\hline \multicolumn{2}{|c|}{ ** 'T'otal *** } & & 129 & \\
\hline
\end{tabular}


The field rames are abbreviated so they can fit into their proper spaces. Following is a description of each field.

1. ITEM - Item name

2. LO'T NUMBER -. Lot number of the item

3. LOCATION - Where the item is located

4. BIN -. A further breakdown of where an item is located

5. LAST_INVTY - Last inventory date

6. INVTY_QUAN - Total quantity at time of the inventory

7. QUAN_USED -. Total number of items used since the last inventory

8. CURNT QUAN - Current quantity of the items since the last inventory

9. UNITS - Brief description (e.g., bx for box, $\mathrm{cn}$ for can, ea for each)

10. UNI'T_W'T - Item explosive weight

11. CURNT_W'T - That item's total explosive weight.
12. OWNER - The person or organization responsible for the item

13. COMMENTS - Any other additional information

14. HAZ CLASS - DOE hazard classification

15. COMP_GROUP - DOE storage compatibility group

\section{Starting the Program}

To start the program, one must be in dBASE 111 or III Plus and at the dot prompt. At the dot prompt, type in DO INVENT. This command starts the program and brings up the first screen (see Figure 1), the user access screen. Here, type in a predetermined access code in order to proceed with the program. This screen can be turned off by editing the INVEN'T program. The access code is not visible on the computer screen.

After typing in the correct access code the program will continue on to the first menu screen (Figure 2). This shows the date and time at the top of the screen along with a menu of six choices.

ENTER USER CODE

Figure 1. User Access Screen

$00 / 00 / 00$

1> UPDATE INVENTORY
2> EDIT OY DELETE RECORD
3> APPEND RECORD
4> INVENTORY LISTING
$5>$ INDEX INVENTORY
6> EXIT PROGRAM
$7>$ EXIT DBASE III PLUS
Enter SELECTiON : :

$00: 00: 00$

Figure 2. Main Menu 


\section{Update Inventory Program}

When selecting the first item on the Main Menu you are entering the UPDATE INVENTORY program. This program performs all the calculations needed to keep the inventory current. 'The program can add items into the inventory, it can take items out, and it can change the inventory date. When adding fo or subtracting from this program it will automatically change the current weight and current quantity. 'The first screen will state:

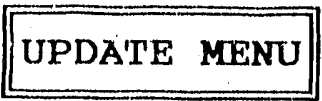

\section{Enter item name}

At this point you have two choices. The first is to press the enter key , which will then state:

\section{UPDATE MENU}

\section{No entry!! Is this correct? (Y or $N$ )}

If you type Yes, the program will search for a record with a blank item field. If no blank item fields are found the next screen will state:

\section{No item found}

\section{Press any key to continue}

Pressing any key will take you back to the main program menu. If you type No, this also will take you back to the main program menu. The second choice is to enter an item name. This could be either a single letter or enough information to make your entry unique. It is to the user's advantage to use as much information as possible. For example, by typing the letter $P$ 'you will get the first record that contains that letter. If there are multiple entries contanning the letter l'press the PgIn key to get to the record you need. Alter you enter the item name the program will state:

\section{Your entry was - (example)}

\section{Is this entry correct? ( $\mathrm{Y}$ or $\mathrm{N}$ )}

A Yes answer will take you to the record. If the record cannot be found, the program states:

\section{No item found}

\section{Press any key to continue}

Pressing any key takes you back to the main program menu. A $N_{0}$ answer also takes you brok to the main program menu. After you have entered the correct item name, the program will search for that particular record. Once the record is found the screen shown in Figure 3 will appear. 'There are three different fields one can change in this program:

\section{QUANTITY REMOVED \\ QUANTIT'Y RECEIVEI) \\ DATE RECEIVED}

The cursor will be flashing at the QUAN'I'T'Y RF.-. MOVED area. Entering an amount here and pushing the enter $k$ ey $>$ will change the TO'TAI, QUAN. TIT'Y USE'I), the CURREN'T QUAN'TITY, and the CURREN'T WEIGH'T. If nothing was removed simply press the Enter key. This will take you to the next field, QUAN'IITY RECEIVED. Entering an amount here will change the INVENTORY QUAN'TIIY, CURREN' QUAN'TITY, and CURREN'T WEIGH'I'. If nothing was received press the <enter key $>$ and this will take you to the last area, the DATE RECEIVED. Entering a date will change the LAS'I INVENTORY DA'TE to the new date. If you don't wish to change the date, press the <enter key $>$. 'This will then add, subtract, or in some way alter the fields in which you have entered changes. If the item you selected has more than one entry, use the Pulp and PgIn keys to get to the proper record. When you are at the end or at the beginning of the file, a message will flash either ENI) OF FILE or BE(IINNINC: OF Fll.ti to advise you of your status. Once a change has heen made, the QUIT option becomes available (Fig. ure 3). Pressing the $Q$ key will take you loack to the main program menu. 


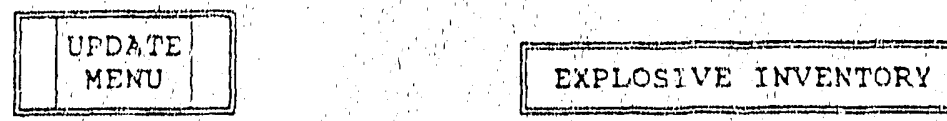

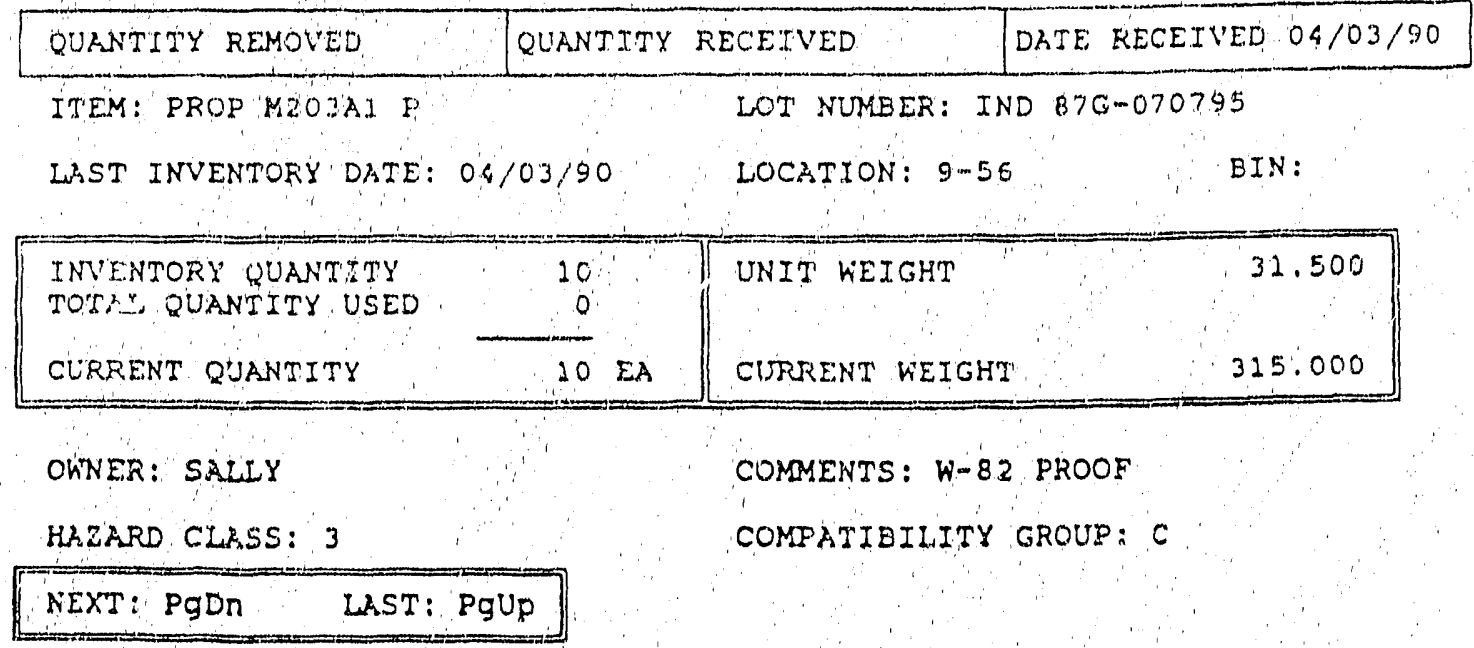

Figure 3. Update Menu

\section{Edit or Delete Record Program}

From the inain program menu, one can select the EDIT or DELETE RECORD program. This program can edit any part of a record or the entire record. The program is also used to delete a record. When deleting a record, you are actually putting a flag on that record. This give you the option to delete it completely or to merely leave the flag in place.

'To use this program at the main menu, select the EDIT or DELETE RECORD program.

NOTE: This program will not do calculations; you must be in the UPDATE program to do any calculations. An exception to this is the AP. PEND program, which is set up to do the original calculations for total item weight. After selectin's the EDIT or DEI,trTE RECORI) program, the first screen states:

\section{EDIT or DELETE MTENU}

You now have two choices. The first is to press the <enter key>, which will then state:

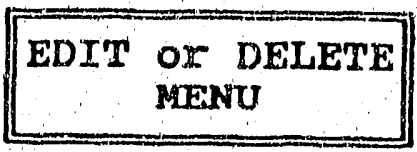

\section{No entry! Is this correct? ( $\mathrm{Y}$ or $\mathrm{N}$ )}

If you type Yes, the program will search for a record with a blank item field. If no blank item fields are found, the next screen will state:

\section{No item found}

\section{Press any key to continue}

Pressing any key will take you back to the main program menu. If you type No, this will also take you back to the main program menu.

Your second choice is to enter an item name. 'This can be either a single letter or enough information to make your entry unique. For example, if you type the letter $P$, you would get the first record containing that letter. If there dre multiple entries containing the

\section{Enter item name}


letter $P$, use the PgDn key to get to the record you need. After you enter the item name, the program slates:

\section{Your entry was - (example)}

\section{Is this entry correct? ( $Y$ or $N$ )}

A Yes answer will take you to that record, unless the record cannot be found. Then the program states:

\section{No item found}

\section{Press äny key to continue}

Pressing any key will take you back to the main program. A No answer will also take you back to the main program menu.
Once you have entered an item name anci it is correct, the program will search for that particular record. When the record is found the screen shown in Figure 4 will appear. You can change any field within this record; however, it is not advisable to change any of the quantities or the weight information. If you do change a quantity or weight, you must run the UP. DA'TE INVENTORY program and toggle through the record that you have changed to do the correcter calculations.

To get to the field you wish to change, press the center key>. 'This moves the cursor from one field to the next. 'To back up or erase an entry, press the back space key and retype.

At the bottom of the screen is a list of commands that can be used and the proper keys to execute the commands (Figure 5).

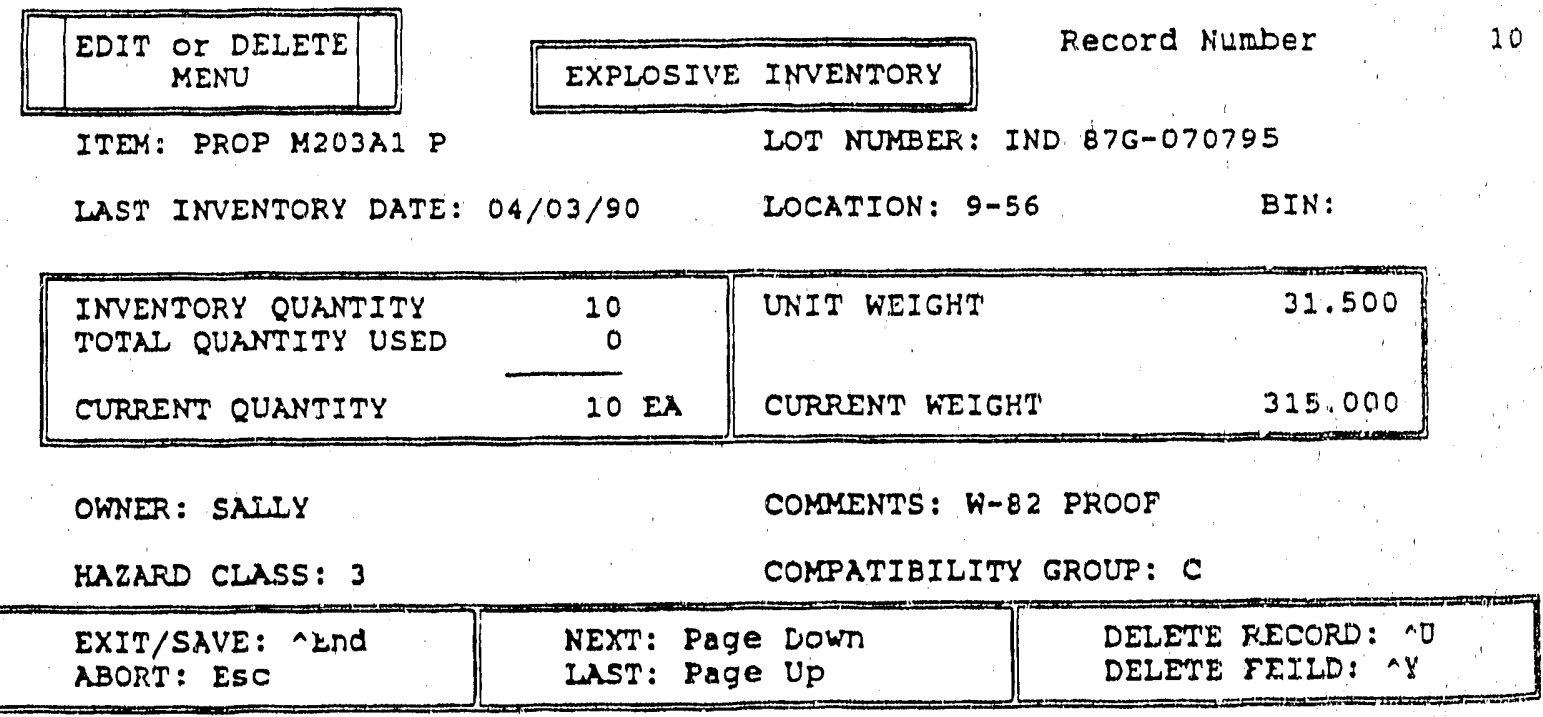

Figure 4. Edit or Delete Menu

$\left.\begin{array}{|l}\text { EXIT/SAVE: ^End } \\ \text { ABORT: ESC }\end{array}\right]\left[\begin{array}{l}\text { NEXT: Page Down } \\ \text { LAST: Page UP }\end{array}\right]\left[\begin{array}{l}\text { DELETE RECORD: } \\ \text { DELETE FIELD : }\end{array}\right.$

Figure 5. Commands Screen 
The EXIT/SAVE command exits the EDIT or DELETE RECORD program and saves the changes that were made. To execute this command, press both the Ctrl key and the End key simultaneously.

The ABOR'T command cancels all changes made on the current record. 'To execule the ABORT' command, press the Esc key.

The NEX'I and LAS'T commands are used to move to the next record or to the previous record. To use this function, press the PgUp for previous record and PgDn for next record.

The DELETE RECORD command is used if you wish to flag a particular record to be deleted from the inventory. To execute the DELETE cominand, press the Ctrl and U keys simultaneously. This will flag the current record. If you flagged the wrong record, press the Ctrl and U keys once more to remove the flag on the record. The status bar at the very bottom of the screen indicates whether a record is flagged. DEL will appear at the right-hand side of the status bar" if the current record is flagged.

The DELETE FIELD command is used to erase a complete field. To execute the DELF'TE FIELD comrrand, press the Ctrl and Y keys simultaneously.

When you exit the program by either the ABORT command or the EXIT/SAVE command, the next screen states:

\section{Do you want to erase from inventory records marked for deletion?}

$(\mathrm{Y}$ or $\mathrm{N}):$ :

A Y'es response will erase all records llagged for deletion. The next screen will state:

\section{!!! Do not interrupt!!!}

\section{!! System is packing ! !!}

'The word packing is a term used by dBASE. A No answer will maintain all records, and flag those marked for deletion. This will not erase any records that are flagged:

\section{Append Record Program}

This program is used to add new records to the inventory. The APPEND RECORD program will temporarily start a new database file, called $\mathrm{HE}$. When the file is finished to your satisfaction it will take the database file and add your new files to the main database, which is called EXPLOSIVE. When you start the APPEND RECORD program, the menu in Figure 6 will show up on your screen. All the data fields will be blank.

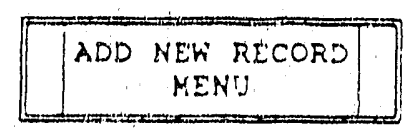

ITEM:

LKST JNTENTORY DAEI:

INENTORY QUANAITY
TOTAL QUANITY USES
CURRENT QUANTIZY

OWNER:

HAZARD CLMSS:

\section{EXPLOSIVE INTENTORY}

LOT NUNEER:

LOCATION:

BIN:
URIT WIIGMT

."

CURRENT KEIGHT

COMMENT'S:

COMPATIBILITY GROUP:

Figure 6. Add New Record Menu 
To append (add) records, simply fill in the blanks. For fields that have no input data, press the center key $>$ to go on to the next field. If you enter an item's init weight it will automatically compute the total current weight of that item.

Three fields require an input: ITEM, LOCATION, and COMPATIBILITY GROUP.

If you leave the ITEM field blank, the screen will state:

\section{No item entry, record will not be added! \\ Press any key to continue}

Pressing any key the next screen will allow you to select one of three items and will look like this:

\section{$1>$ Edit this entry \\ $2>$ Next entry \\ 3>Quit}

\section{Make Selection : :}

At this point you can select 1 or 3 ; selecting 2 would be of no use. If you select 1 , this will allow you to go back and add an item name or change any other field. If you select 3 , this will take you back to the main program menu.

If you leave the LOCATION field blank the screen will look like this:

\section{Not a compatible location \\ Enter new location \\ Enter compatibility group}

With this screen yoi must input a location and a compatibility group letter.

If you leave the COMPATIBILI'TY GROUP field blank, the screen will look like this:

\section{Not a valid compatibility group! \\ Enter valid compatibility group}

In the compatibility group is a very important item that must be correct. 'T his has a check and balance system. Once the program is set up to accommodate your needs, this will check that what you are storing into a particular igloo is compatible with what is already stored. There are three diflerent scenarios:

1. If you stored an item that is 100 'i compati. ble, the screen that you will see tifter it does all the checks is:

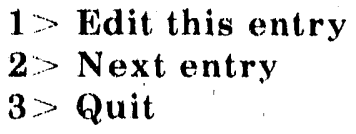

\section{Make selection : :}

From this screen you may select 1 to edit any or all of the entry, 2 if you plan to add another item, or 3 if you are finished. 'This will take you back to the main program menu.

2. If it is 50" compatible-- that is, compatible with what is already stored but maybe there is a better location available---the screen will show:

Is there a better location available? ( $Y$ or $\mathbf{N}$ )

A Yes response will prompt you for a new location. Type in new location and press Enter. It will recheck all the entries for discrepancies. A No response will bring back the screen:

\section{$1>$ Edit this entry \\ $2>$ Next entry \\ 3> Quit}

3. If it is not compatible at all, this will prompt. a scroen staling:

Not a compatible location Enter new location Enter compatibility group

Enter a new location and a compatibility group. Let the program check again to see if there are any problems. If everything is all right, the next screen will state:

\section{$1>$ Edit this entry \\ 2> Next entry \\ 3> Quit}

To exit this program select 3. This will take you back to the main program menu. 


\section{Inventory Listing Program}

From the main menu, selecting the INVEN. 'TORY LISTING program will bring you to the next menu, which offers six options:

$1>$ MAIN REPORT
$2>$ OWNER REPORT
$3>$ WEIGHT REPORT
$4>$ ANNUAI REPORT
$5>$ LABEI MAKER
$6>$ EXIT
ENTER SELECTION :

The first selection, MAIN REPOR'T, will print out an overview of the explosive inventory (Figure 7).

The second selection, OWNER REPORT, will print out a report showing what items belong to what owner (Figure 8).
'The third selection, WEIGHT' REPORT, will print out a report giving total explosive weight by item and per bunker (Figure 9).

The fourth selection, ANNUAI, REPORT, gives the annual summary report (Figure 10).

LABEl, MAKER, the fifth selection, enables the user to make labels for each item in the inventory. When selecting LABEL MAKER, the next screen you will see is a menu with two selections.

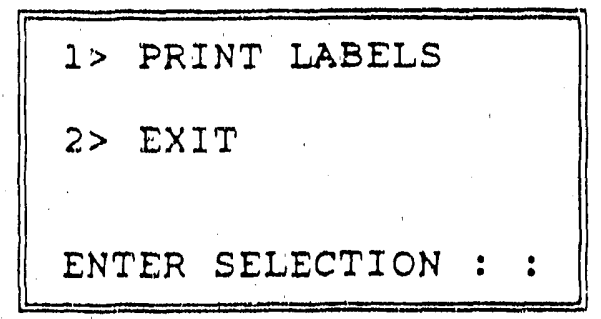

\begin{abstract}
Page No. 1
$04 / 25 / 90$
\end{abstract}

ITEM

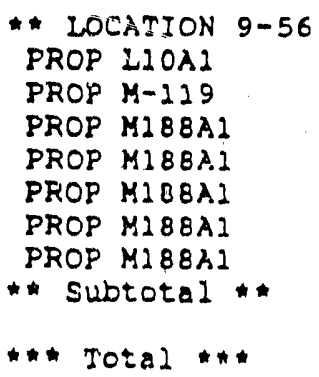

TONOPAH TEST RANGE

EXPLOSIVE

STORAGE INVENTORY

LOT/PART NUMBER

BIN TOTAI

UNITS
$26 \mathrm{EA}$

39 EA

7 EA

6 EA

12. EA

$7 E A$

$12 E A$

99

99
COMNENTS

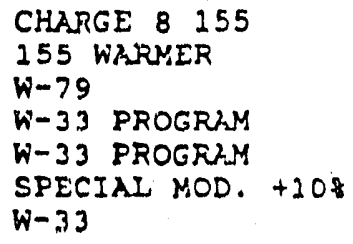

Figure 7. MAIN REPOR' Printout 


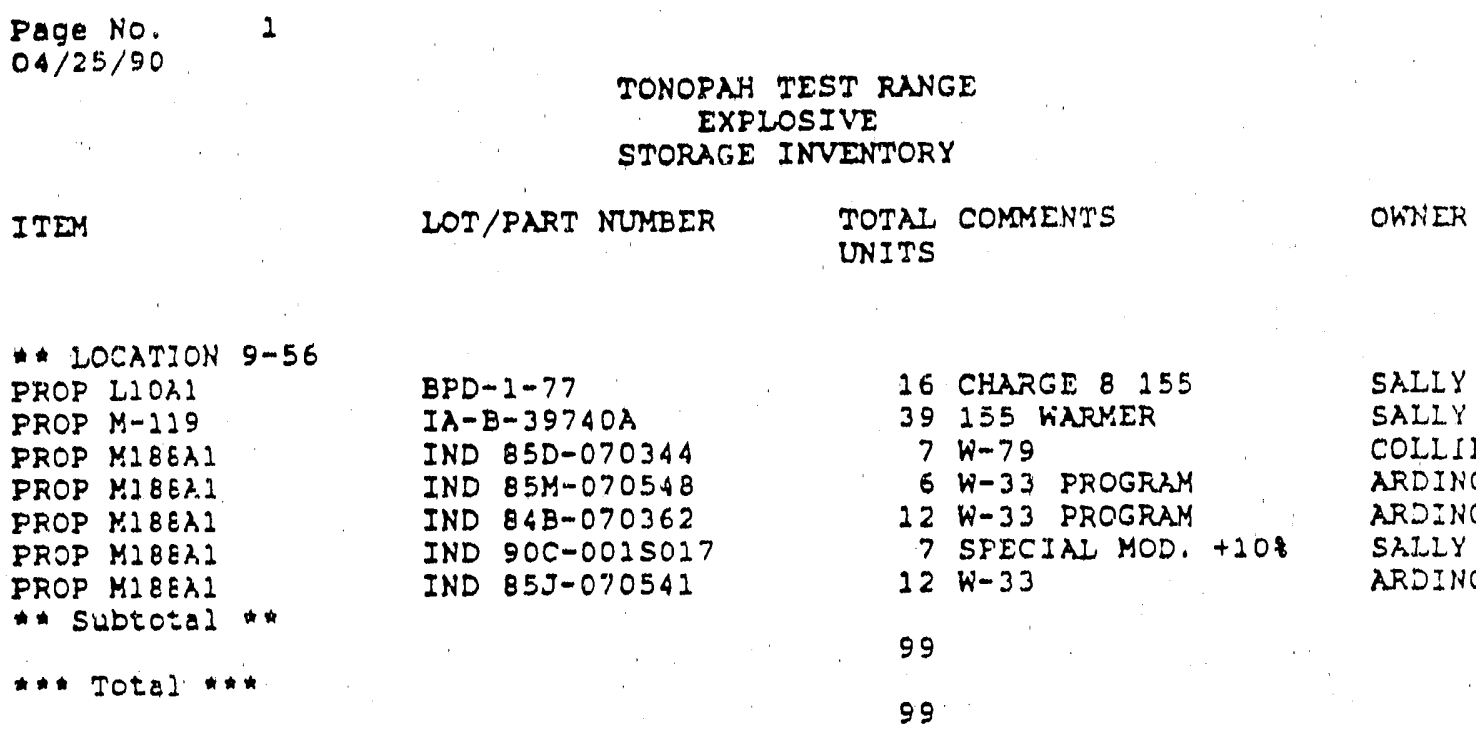

99

Figure 8. OWNER REPORT Printout

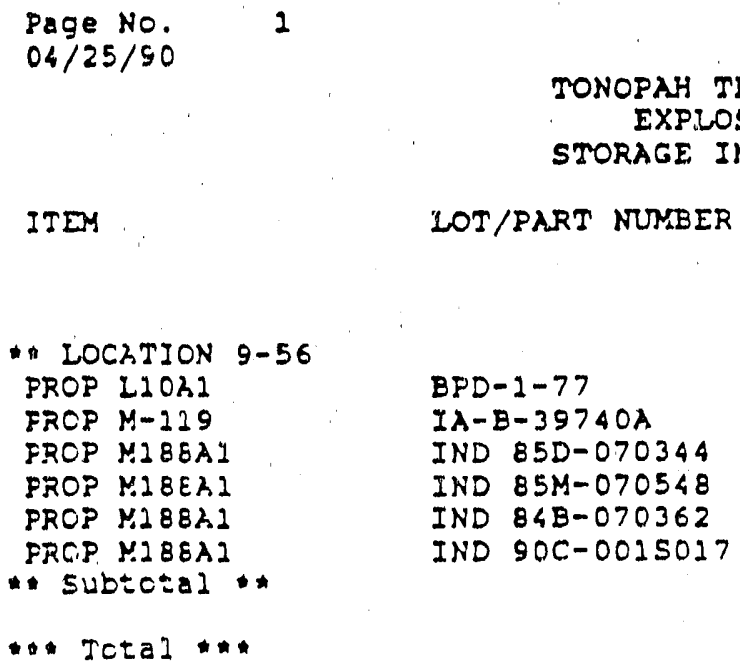

TOTAL

WEIGHT

$\begin{array}{ll}\text { CHLRGE } 8155 & 480.000 \\ 255 \text { WLRMER } & 897.000 \\ W-79 & 364.000 \\ W-33 \text { PROGRAM } & 322.000 \\ W-33 \text { PROGRMM } & 624.000 \\ \text { SPECIAI MOD. +208 } & 312.900 \\ & 2989.900 \\ & 2989.900\end{array}$

Figure 9. WEIGHT REPOR' Printout 


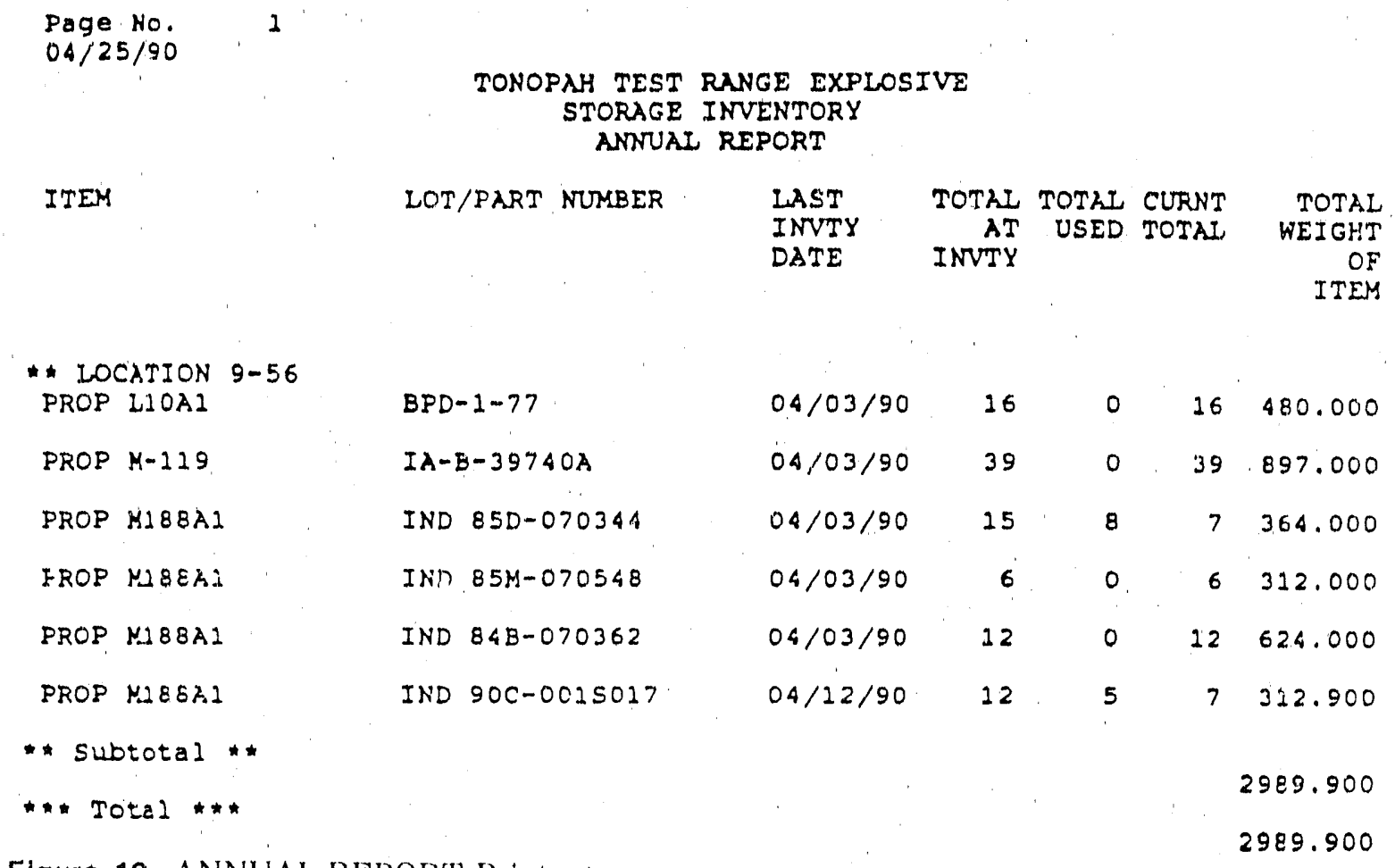

Figure 10. ANNUAL REPOR'T Printout

When you select the first item, PRINT LABELS, the next screen shows:

\section{LABEL MENU}

\section{Do you want a printout of the inventory?} Y or N : :

A Y'es answer will give a printout showing the record number, item, lot number, and current quantity of the entire inventory. Figure 11 shows an example.

A No answer will take you to the next screen, which will ask for the record number of the item for which a label is to be printed. The record number can be found on the printout, but once you have a printout you don't need another unless you have made additions or deletions to the inventory. Enter the record number. The next screen will state:

\section{Your entry was -}

Is this entry correct? ( $\mathrm{Y}$ or $\mathrm{N}$ )

A No response will take you back to the menu for this program; a Yes response will print out the record you chose. Press any key to continue. The next screen will state:

\section{LABEL \\ MAKER}

\section{Enter number of labels to print}

Enter the number of labels you need and press Return. The next screen will state:

\section{Your entry was -}

Is this entry correct? ( $\mathrm{Y}$ or $\mathrm{N}$ ) 
A No answer will take you back to the main menu for this program. A Y'e's answer will print out the number of labelc requested. Figure 12 gives an example of a few labels. Each label shows the item, the lot or serial number, any comments that might further descrike the item, who owns the item, and the last date it was inventoried. After the labels have been printed the next screen will be the label menu. At this point you may print more labels or exit. Pressing the exit key will take you to the main program menu.

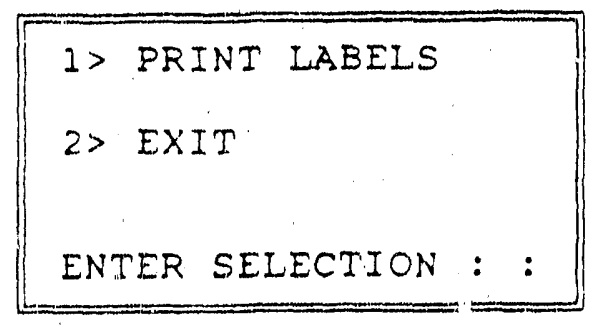

LOT NUMBER

$B P D=1-77$

$I A-B=39740 A$

IND $85 D-070344$

IND $85 \mathrm{M}-070548$
CURNT_QUAN

16

39

8

6

Figure 11. Inventory Printout

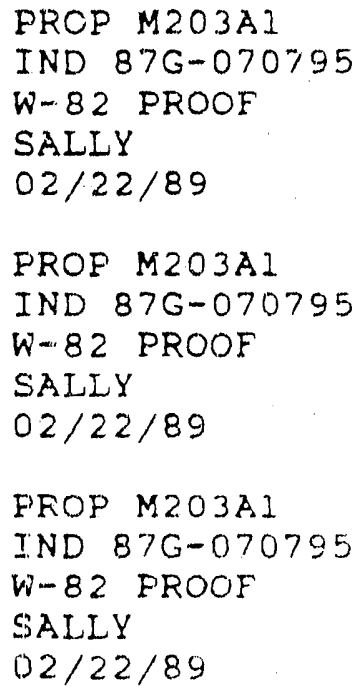

Figure 12. Fxample of Labels

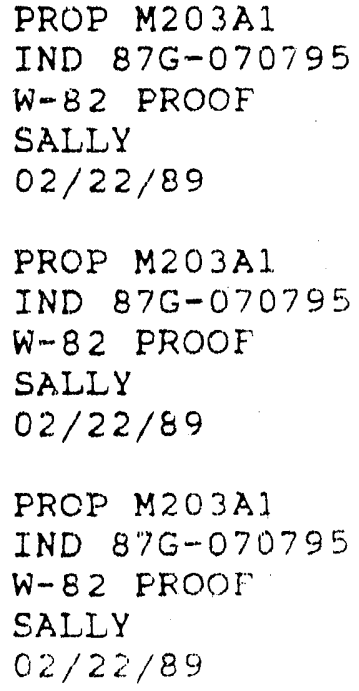



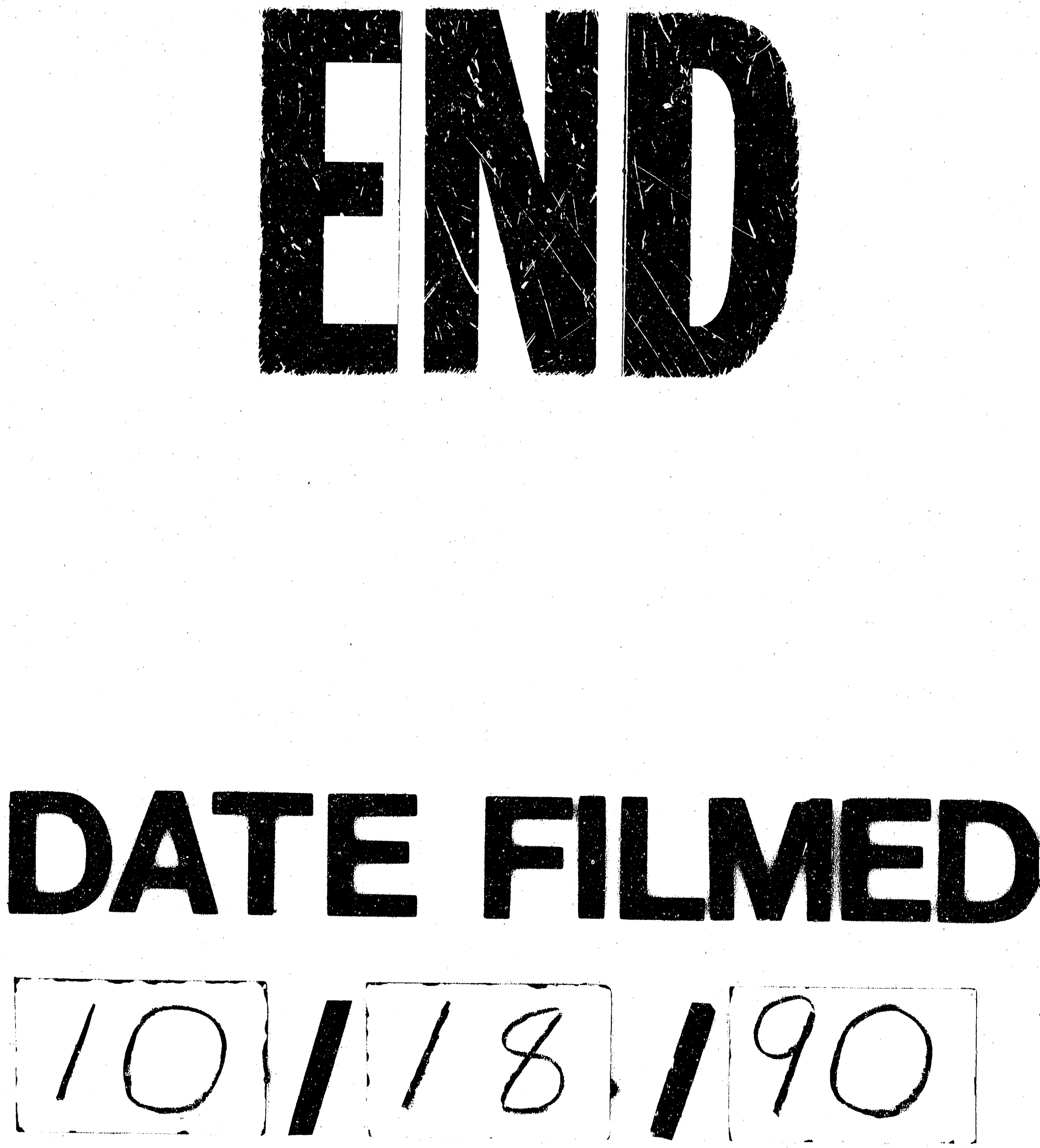
